\title{
A STUDY OF THE TRANSVERSE CERVICAL AND DORSAL SCAPULAR ARTERIES
}

\author{
DONALD F. HUELKE \\ Department of Anatomy, University of Michigan Medical School, \\ Ann Arbor, Michigan \\ FOUR FIGURES
}

\section{INTRODUCTION}

In most anatomical accounts the transverse cervical artery is described as having two major branches: an ascending and a descending. As a variant, the descending branch arises separately, usually as a direct branch of the third part of the subclavian artery. According to the recent Paris revision of anatomical nomenclature (N.A.P., '55), the transverse cervical artery, of the thyrocervical trunk, gives rise to a superficial and a deep branch; these terms, superficial and deep, replace ascending and descending. When, as a variation, these two branches arise separately, they are then given the names, "superficial cervical artery" and "descending seapular artery," respectively. As it stands, then, each artery may be called by either one of two names-depending upon its origin.

One of the principles adopted by the International Anatomical Nomenclature Committee was, "that structures closely related topographically shall, as far as possible, have similar names." Thus, for example, the transverse scapular artery and vein now have the name "suprascapular," to correspond to the nerve which accompanies them. Furthermore, the Committee also adopted the principle: "that, with a very limited number of exceptions, each structure shall be designated by one term only." On the basis of these principles, it is here suggested that the term "dorsal scapular artery" replace the terms "deep branch of the transverse cervical artery" and 
"descending scapular artery" since the terminal course of the artery in question is downward along the medial border of the scapula where it accompanies the dorsal scapular nerve and supplies branches to the rhomboid muscles.

As shown hereafter, the dorsal scapular artery is more often a direct branch of the subclavian artery than a branch of the transverse cervical artery and, thus, its occurrence as a branch of the transverse cervical artery is the variation, not the usual case. With this change in terminology, the term "transverse cervical artery" is restricted to that artery which, in its terminal course, is found deep to the trapezius where it supplies primarily the middle third of this muscle. The terms "superficial branch of the transverse cervical artery" and "superficial cervical artery" then become unnecessary.

It is the purpose of this paper to show that the dorsal scapular artery has an origin from the subclavian artery (apart from the transverse cervical artery of the thyrocervical trunk) in nearly $70 \%$ of the sides examined and, for this reason, requires recognition as a separate vessel. A description of the course, branches, and distribution of both the transverse cervical and dorsal scapular arteries is given in order to clarify their relationships.

\section{MATERIAL}

The data for this report were recorded from 89 adult cadavers of which 79 were Caucasian (60 males and 19 females) and 10 were Negro ( 7 males and 3 females). Both right and left sides were used; a total of 178 sides were observed.

RESULTS AND DISCUSSION

\section{The dorsal scapular artery}

The dorsal scapular artery almost always arises from the second or third part of the subclavian artery or from the transverse cervical artery; it arises from each one of these sites in approximately $33 \%$ (table 1, fig. 1). When the dorsal scapular artery comes from the second or third part of the subclavian 
TABLE I

The number and frequency of occurrence of the various sites of origin of the dorsal scapular artery

\begin{tabular}{lrr}
\hline \multicolumn{1}{c}{ ORIGIN } & PUMBER & PER T \\
\hline A. From the transverse cervical artery & 54 & 30.3 \\
B. From subclavian II & & \\
1. directly & 54 & 30.3 \\
2. with the costocervical trunk & 2 & 1.1 \\
3. With the suprascapular artery & 4 & 2.2 \\
C. From subclavian III & 55 & 30.9 \\
1. directly & 1 & 0.6 \\
2. with the costocervical trunk & 3 & 1.7 \\
3. with the suprascapular artery & & \\
Direetly from: & 1 & 0.6 \\
1. thyrocervical trunk & 1 & 0.6 \\
2. subclavian I & 2 & 1.2 \\
3. axillary I & 1 & 0.6 \\
4. axillary II & & \\
\hline
\end{tabular}

The subelavian artery was considered to be divided into three parts by the anterior scalene muscle. The segment of the artery medial to the muscle is subelavian I; the portion behind it is subclavian II, and the part of the artery lateral to the muscle is subclavian III.

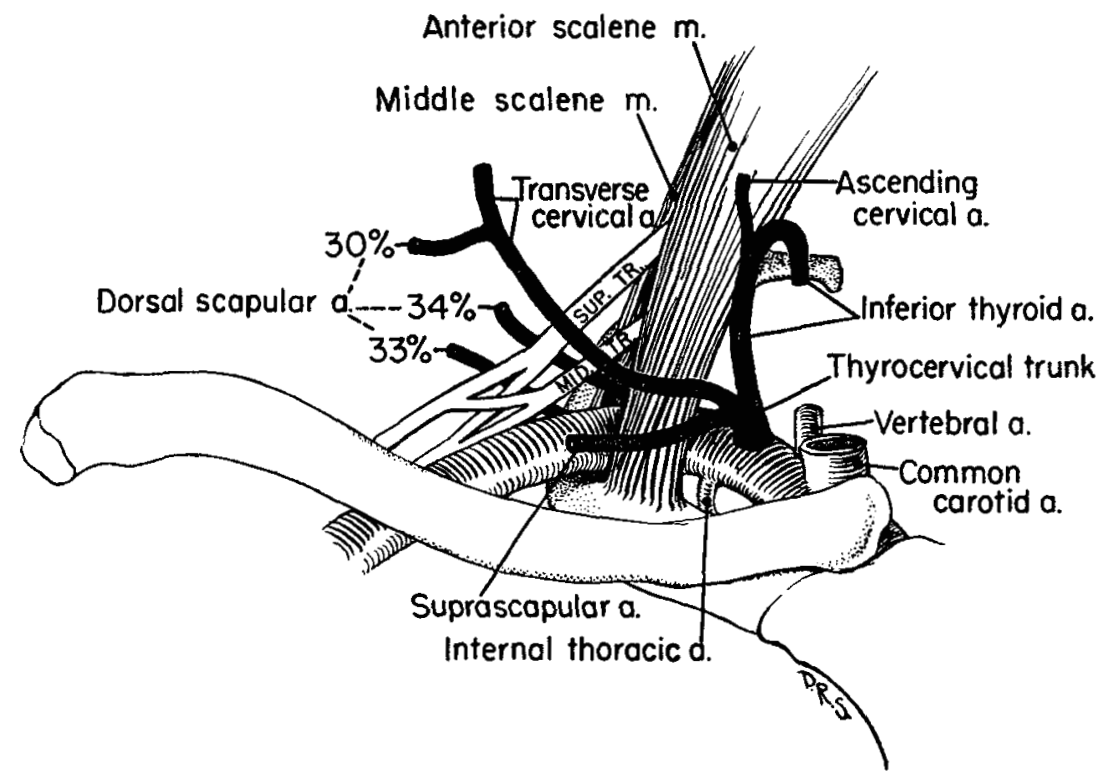

Fig. 1 The three major sites of origin of the dorsal scapular artery. 
artery it is usually a separate branch, rather than from a stem common to it and to either the costocervical trunk or the suprascapular artery. It is rare for the dorsal scapular artery to arise, as a direct branch, from the first part of the subclavian artery, the axillary artery, or the thyrocervical trunk. Thus, the dorsal scapular artery, traditionally considered a branch of the transverse cervical artery (its deep branch), actually has an origin more frequently $(69.7 \%)$ from some other source.

TABLE 2

The frequency of the various sites of origin of the dorsal scapular artery as reported by other investigators ${ }^{1}$

\begin{tabular}{|c|c|c|c|c|}
\hline \multirow[b]{2}{*}{ AUTHOR } & \multirow{2}{*}{$\begin{array}{l}\text { FROMT THE } \\
\text { TRANSVERSE } \\
\text { CERVICAL } \\
\text { ARTERY }\end{array}$} & \multicolumn{2}{|c|}{ FROM THE SUBCLAVIAN ARTERY } & \multirow[b]{2}{*}{ OTHER } \\
\hline & & $\begin{array}{l}\text { Second } \\
\text { part }\end{array}$ & $\begin{array}{l}\text { Third part } \\
\text { (or } \\
\text { Axillary A.) }\end{array}$ & \\
\hline & $\%$ & $\%$ & 6 & $\%$ \\
\hline 'Thompson. & 50.7 & 2.6 & 46.7 & 一 \\
\hline DeGaris & 45.7 & 2.2 & 52.1 & - \\
\hline Adachi & 53.8 & 23.1 & 22.1 & 1.0 \\
\hline Röhlich & 28.0 & 25.5 & 45.0 & 1.5 \\
\hline
\end{tabular}

${ }^{1}$ In these investigations the following terms were given to the ressel which is here called the dorsal scapular artery: transverse colli (Adachi and Röhlich); posterior scapular (Thompson); descending branch of the transverse cervical artery (DeGaris).

The data on the origin of the dorsal scapular artery as found by other authors are recorded in table 2. Thompson (1891), DeGaris ('24), and Adachi ('28) found that it arose from the transverse cervical artery, of the thyrocervical trunk, in approximately one-half of their series; in the other $50 \%$ of their material the dorsal scapular artery arose from the subclavian artery. Röhlich ('34) indicated that the origin of the dorsal scapular artery is directly from the subclavian artery in $70 \%$. Only Adachi and Röhlich reported other types of origin, but these were rare and infrequent.

The course of the dorsal scapular artery is variable (fig. 2). ${ }^{1}$ When it arises directly from the second or third part of the

${ }^{1}$ The percentages were calculated from the data of 84 sides for, of the 124 dorsal scapular arteries which did not arise from the transverse cervical artery, the relationship to the brachial plexus was destroyed on 40 sides. 
subclavian artery, the dorsal scapular artery passes between the middle and inferior trunks (or the posterior division of the inferior trunk) of the brachial plexus in two-fifths of the sides. With the same frequency the artery passes between the middle trunk and the superior trunk, or its posterior division. Rarely it passes between the roots of $\mathrm{C} 8$ and $\mathrm{T} 1$ or between the posterior and lateral cords. In three cases the dorsal scapular artery, arising directly from the third part of the sub-

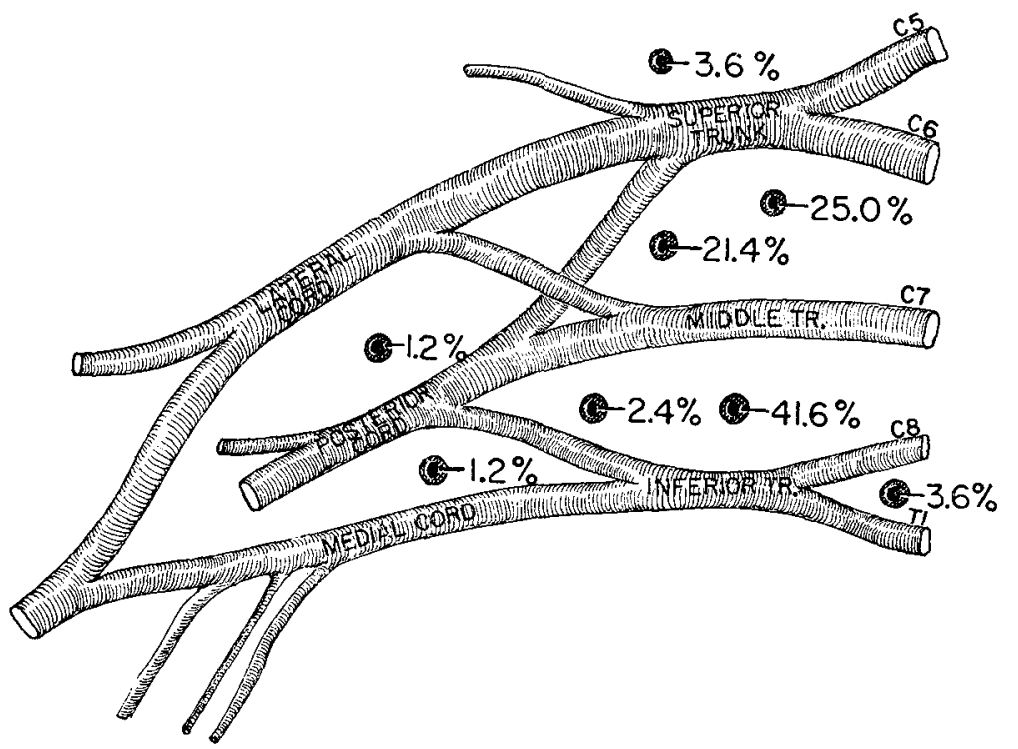

Fig. 2 The frequeney of the various positions of the dorsal seapular artery as it passes through the brachial plexus.

clavian artery, passed over the plexus. In one instance the artery, arising from the first part of the axillary artery, passed under the posterior cord of the plexus.

At times a dorsal scapular artery, arising from the second or third part of the subclavian artery, is intimately related to the middle or posterior scalene muscle. Usually the artery passes lateral to these muscles, but in $26.6 \%$ of cases the artery passes through or medial to either or both of these scalene muscles. When the dorsal scapular artery arises from the 
transverse cervical artery, its origin is always near the superior border of the scapula; the artery in this location is posterior and above the brachial plexus and, therefore, it is never found passing through the plexus. Such arteries are always lateral to the scalene muscles.

After passing through the brachial plexus, the dorsal seapular artery passes over the upper, free margin of the serratus anterior muscle. It then angles downward and medialward, on the costal surface of this muscle, to reach the medial border of the scapula in the region of the base of the scapular spine. This course differs from that taken by a dorsal scapular artery which arises from the transverse cervical artery. Here, the dorsal scapular artery (arising near the superior angle of the scapula) turns directly downward along the medial border of the scapula.

\section{The transverse cervical artery}

The transverse cervical artery exhibits the following variations in its origin (fig. 3 ) :

Type I. The artery has its origin with the suprascapular artery by a common stem arising from the thyrocervical trunk.

Type II. The artery arises directly from the thyrocervical trunk.

Type III. The artery arises from the dorsal scapular artery.

Type IV. The artery arises from the internal thoracic artery.

The data on these various types of origin are presented in table 3. The transverse cervical artery arises from the thyrocervical trunk, by a stem common to it and to the suprascapular artery (type I) in $40.4 \%$ of the sides in this series. This common stem is occasionally very long, extending close to the superior angle of the scapula before dividing. Such a long stem occurred in 11 of the 72 sides. When one considers its frequency in relation to the total number of sides examined (178), the occurrence of this long common stem is rare.

The origin of the transverse cervical artery directly from the thyrocervical trunk (type II) is slightly less frequent than 
the type I origin; it occurs in $37.1 \%$ of all sides. The transverse cervical arteries classified as types I and II have an origin from the thyrocervical trunk in common and, for this reason, they can be combined. Thus, the transverse cervical artery arises from the thyrocervical trunk in three-fourths $(77.5 \%)$ of all sides.
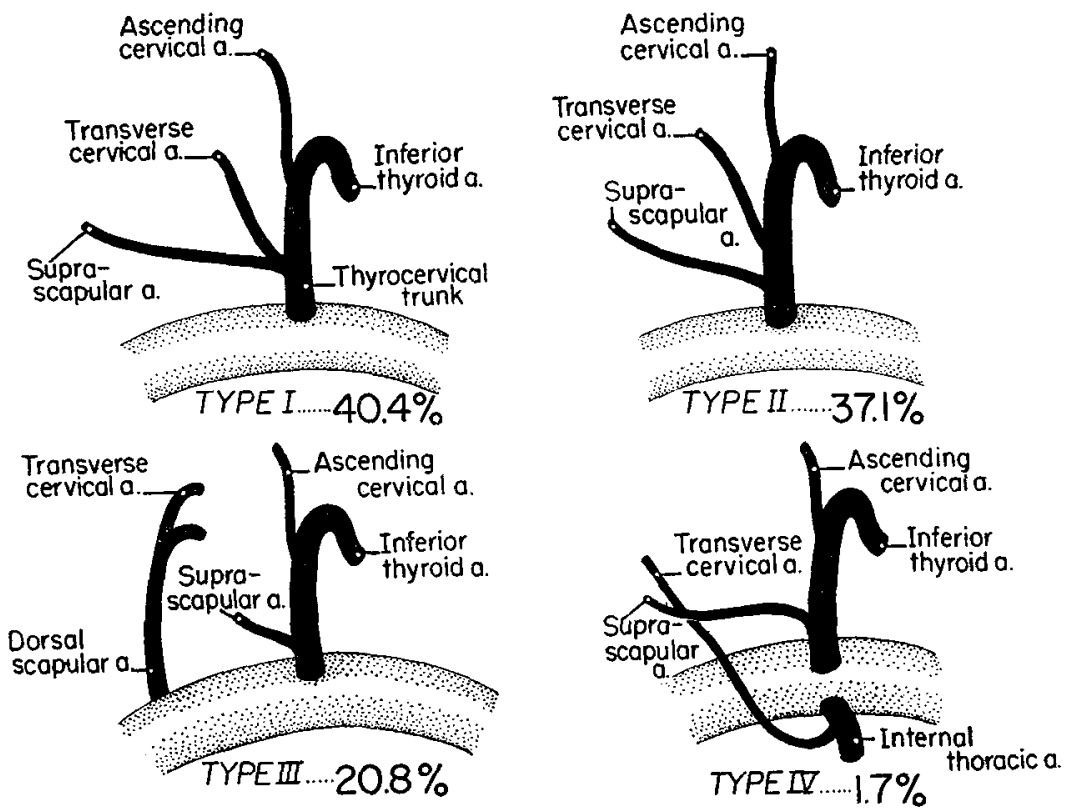

Fig. 3 The variations in the origin of the transverse cervical artery.

In one-fifth of the sides, the transverse cervical artery was a branch of the dorsal scapular artery. Such a transverse cervical artery (type III) arises from the dorsal scapular artery near the superior border of the scapula. In these cases, the dorsal scapular artery arises directly from the second or third part of the subclavian artery. After arising from the dorsal scapular artery, the transverse cervical artery passes over the scapula just lateral to the levator scapulae muscle and turns downward along the deep surface of the trapezius muscle. One cannot classify this as a transverse cervical artery 
giving rise to a dorsal scapular artery, for an origin from the second or third part of the subclavian artery is typical of the dorsal scapular artery and not of the transverse cervical artery. In these cases the thyrocervical trunk did not give rise to any branches to the trapezius muscle which could possibly be referred to as a transverse cervical artery.

Rarely the transverse cervical artery arises from a source other than one of those mentioned above. On three sides it was seen to originate from the first part of the subclavian artery with the internal thoracic artery (type IV).

TABLE 3

The frequency of the types of origin of the transverse cervical artery as found in this study compared with other investigations

\begin{tabular}{|c|c|c|c|c|c|}
\hline \multirow{3}{*}{ AUTHOR } & \multicolumn{5}{|c|}{ ORIGIN } \\
\hline & \multicolumn{3}{|c|}{ From the Thyrocervical Trunk } & \multirow[b]{2}{*}{$\begin{array}{l}\text { From the } \\
\text { dors. scap. a. } \\
\text { (Type III) }\end{array}$} & \multirow[b]{2}{*}{$\begin{array}{l}\text { From the } \\
\text { int. thor. a } \\
\text { (Type IV) }\end{array}$} \\
\hline & $\begin{array}{l}\text { With the } \\
\text { suprascap. } \\
\text { (Type I) }\end{array}$ & $\begin{array}{l}\text { Directly } \\
\text { (Type II) }\end{array}$ & $\begin{array}{l}\text { Combined } \\
\text { (Types I } \\
\text { and II) }\end{array}$ & & \\
\hline & \%o & $\%$ & $\%$ & $\%$ & $\%$ \\
\hline Huelke & 40.4 & 37.1 & 77.5 & 20.8 & 1.7 \\
\hline Thompson $^{1}$ & 11.8 & 75.1 & 86.9 & 12.7 & 0.4 \\
\hline DeGaris $^{1}$ & 10.4 & 81.0 & 91.4 & 7.9 & 0.7 \\
\hline Read and Trotter & 48.4 & 22.4 & 70.8 & 28.9 & 0.3 \\
\hline
\end{tabular}

"Thompson and DeGaris used the terms, "superficial cervical artery" or "ascending branch of the transverse cervical artery" to denote that vessel which is called the transverse cervical artery in this study.

The variations in origin of the transverse cervical artery as recorded by other investigators are also presented in table 3. It is apparent that the frequency of occurrence of the various types of origin is rather different among the authors. The illustrations of Thompson (1891) and of DeGaris ('24) show the transverse cervical artery arising most frequently as a direct branch of the thyrocervical trunk. This origin far outnumbers any other. In both of these studies, an origin from the dorsal scapular artery is infrequent. By combining their types I and II, it will be noted that the transverse cervical artery has an origin from the thyrocervical trunk in approximately $90 \%$ of their cases; this is about $12 \%$ greater than 
found in the present study. The data of Read and Trotter ('41) agree quite closely with that of this study. They found that the transverse cervical artery arose from the thyrocervical trunk in $70.8 \%$ and from the dorsal scapular artery in $28.9 \%$. All authors agree that it is rare for the dorsal scapular artery to arise from the first part of the subclavian artery in common with the internal thoracic artery.

\section{The branches of the transverse cervical and dorsal scapular arteries}

Most of the branches of the transverse cervical and dorsal scapular arteries arise near the superior border of the scapula just lateral to the levator scapulae muscle. Usually they are quite small. With but two exceptions these branches originate from either the transverse cervical or the dorsal scapular artery but an origin from the transverse cervical artery is the more frequent. Most of these vessels are illustrated in figure 4 .

In the majority of cases $(89.1 \%)$ the dorsal scapular artery gives rise to a "muscular perforating artery." This vessel arises from the dorsal scapular artery on a level with the base of the scapular spine. After passing one to three centimeters medial to the medial border of the scapula, it pierces one of the rhomboid muscles, or traverses the interval between the rhomboideus major and minor muscles. By this means it gains the deep surface of the trapezius where it supplies the lower third of this muscle. The muscular perforating artery always arises from the dorsal scapular artery and never from the transverse cervical artery. Because of its high frequency of occurrence, it is felt that this, the muscular perforating artery, should be recognized as a significant branch of the dorsal scapular artery.

In $14 \%$ of sides the ascending cervical artery arose from the transverse cervical artery; this origin was always very near the thyrocervical trunk.

An artery to the supraspinatus muscle is present in $41 \%$ of cases. It passes over the superior border of the scapula and 


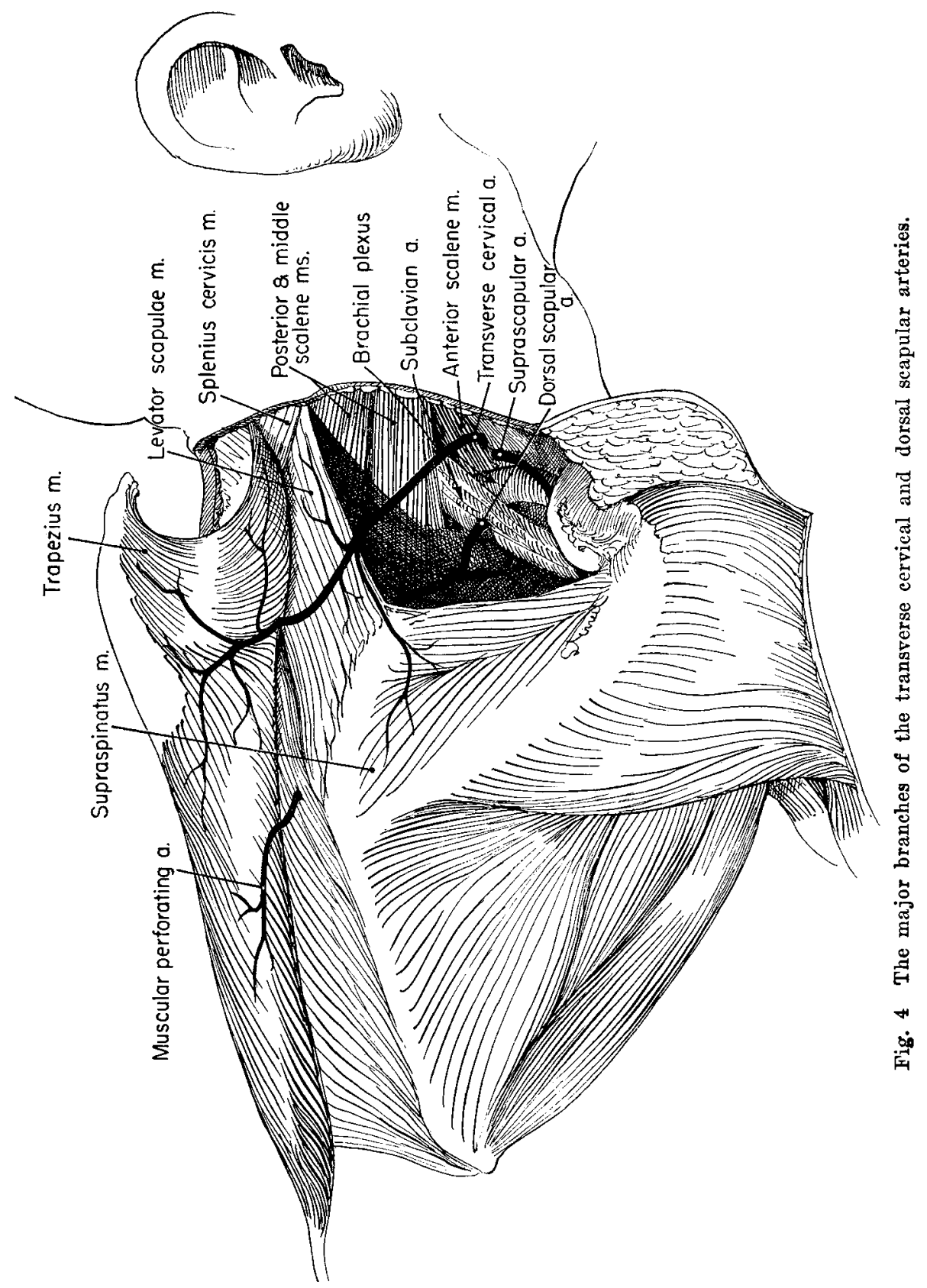


onto the surface of the supraspinatus muscle where it supplies the medial one-third of this muscle. It arises from the transverse cervical artery in $29.2 \%$ of sides and from the dorsal scapular artery in $11.8 \%$.

An ascending branch, of either the transverse cervical or the dorsal scapular artery, was seen in $33.2 \%$ of sides. It passes upwards just beneath the anterior edge of the trapezius muscle to supply, in these cases, the upper one-third of the trapezius muscle. Its origin is more often from the transverse cervical artery $(28.1 \%)$ than from the dorsal scapular artery $(5.1 \%)$.

Small, single or multiple twig-like arteries supply the lower portion of the levator scapulae muscle. They are present in $34.8 \%$, arising from the transverse cervical artery in $18 \%$ and from the dorsal scapular artery in $16.8 \%$. In addition, a definite branch, about the size of the ascending cervical artery, passes upward along the lateral edge of the levator scapulae muscle supplying it throughout its course. It is present in $10.7 \%$ of sides and arises more frequently from the transverse cervical artery $(9.6 \%)$ than from the dorsal scapular artery $(1.1 \%)$.

Other branches, arising in the general area of the superior border of the scapula, pass to the superomedial portion of the subcapularis muscle $(3.9 \%)$, and to the clavicular or acromial portion of the trapezius muscle $(4.5 \%)$. In the latter case, the artery reaches the trapezius muscle by passing through the subtrapezial fat overlying the supraspinatus muscle. When present it replaces the acromial branch of the suprascapular artery.

At least one of the aforementioned branches arose from the transverse cervical or the dorsal scapular artery in virtually every case. In only $8 \%$ of sides did neither of the arteries have such branches.

SUMMARY

The term "dorsal scapular artery" is proposed as a remedy for the confusion in nomenclature concerning the transverse cervical artery and its branches. The dorsal scapular is that 
artery which, in its terminal course, passes with the dorsal scapular nerve near the medial border of the scapula and primarily supplies the rhomboid muscles. The use of this term is in accordance with the principles of nomenclature adopted by the International Committee on Nomenclature.

The dorsal scapular artery arises from the second or third part of the subclavian artery in $67 \%$ of sides. It is a branch of the transverse cervical artery in only $30 \%$. Other sites of origin are rare.

When the dorsal scapular artery arises from the subclavian artery it passes either between the middle and superior trunks $(46 \%)$ or the middle and inferior trunks $(44 \%)$ of the brachial plexus. In $10 \%$ it passed through the plexus in other locations.

The transverse cervical artery is that artery which is found deep to the trapezius where it supplies the middle third of this muscle. It arises from the thyrocervical trunk in the majority of cases $(77.5 \%)$, either as a direct branch $(37.1 \%)$ or from a stem common to it and to the suprascapular artery (40.4\%). The transverse cervical artery arises from the dorsal scapular artery in one-fifth of sides. Only rarely did it arise from the first part of the subclavian artery in common with the internal thoracic artery.

Usually the branches of the transverse cervical and dorsal scapular arteries arise near the superior border of the scapula just lateral to the levator scapulae muscle. An artery to the supraspinatus muscle was present in two-fifths of sides; in one-third of the sides an ascending branch for the supply of the upper third of the trapezius muscle was found.

Small twig-like branches to the lower part of the levator scapulae muscle were found in one-third of the sides. In addition, an artery extending along the edge of the levator scapulae muscle occurred in $10 \%$.

Other branches to the subscapularis muscle and to the clavicular or acromial portions of the trapezius muscle were present but each occurred in less than $5 \%$. 
Most of the aforementioned arteries arose more frequently from the transverse cervical artery than from the dorsal scapular artery.

In almost all cases $(89 \%)$, the dorsal scapular artery gave rise to a "muscular perforating artery" which pierced the rhomboid muscle layer to supply the lower third of the trapezius muscle. The dorsal scapular artery, arising from the subclavian artery, gave rise to the transverse cervical artery in one-fifth of sides.

The ascending cervical artery arose from the transverse cervical artery in $14 \%$. This origin was very near the thyrocervical trunk.

\section{LITERATURE CITED}

ADACHI, B. 1928 Das Arteriensystem der Japaner. Bd. 1, Kyoto.

Cunningham, D. 1951 Textbook of Anatomy. Ed. J. C. Brash. Oxford University Press, New York. p. 1278.

DEGaris, C. 1924 Patterns of branching of the subelavian artery in White and Negro stocks. Am. J. Phys. Anthrop., $7:$ 95-107.

GraY, H. 1954 Anatomy of the Human Body. Ed. C. M. Goss. Lea and Febiger, Philadelphia. pp. 652 and 655.

Morris, H. 1953 Human Anatomy. Ed. J. P. Schaeffer. The Blakiston Co., Sect. VI, pp. 669 and 675 .

READ, W. T., AND M. TRotTER 1941 The origins of the transverse cervical and of the transverse scapular arteries in American Whites and Negroes. Am. J. Phys. Anthrop., 28: 239-247.

Röнlich, K. 1934 Über die arteria transversa colli des Menschen. Anat. Anz., $79: 37-53$.

Thompson, A. 1891 Second annual report of the Committee of Collective Investigation of the Anatomical Society of Great Britain and Ireland for the year 1890-1891. J. Anat. Physiol., 26: 77-80. 